\title{
PROPOSTA LOCACIONAL PARA UNIDADES DE PROCESSAMENTO DE MAMONA PELA AGRICULTURA FAMILIAR, NO CENTRO NORTE DO ESTADO DA BAHIA ${ }^{1}$
}

\author{
Marco Antônio Sartori ${ }^{2}$ \\ Fátima Machado de Souza Lima \\ Ronaldo Perez ${ }^{4}$ \\ Mauro Nacif Rocha ${ }^{5}$ \\ Danielle Dias Sant'Anna Martins ${ }^{6}$
}

\begin{abstract}
Resumo: Este trabalho avalia locais para instalação de unidades de produção de óleo vegetal de mamona na região centro-norte do estado da Bahia. Na região existem 55 municípios produtores de mamona, e a cidade de Candeias será o destino do óleo vegetal produzido, em razão da instalação da unidade de produção de biodiesel da PETROBRAS. Com a finalidade de garantir a participação da agricultura familiar, o estudo considera unidades de processamento de pequena escala, com capacidades de processamento de 7,5 e 22,5 toneladas/dia de mamona. Para a solução, desenvolveu-se um modelo matemático, utilizando o software XPRESS MP Release, 2007, considerando as produções nos municípios, as distâncias entre as áreas de produção agrícola e as cidades candidatas ao esmagamento, e destas até a usina de produção de biodiesel. Como resultado, obteve-se a indicação de oito cidades potenciais para instalação de plantas de produção de óleo vegetal, de forma a minimizar o custo logístico.
\end{abstract}

Palavras-chave: Localização, óleo de mamona, custos de transporte.

\footnotetext{
${ }^{1}$ Recebido em 02/09/08; Aceito em 28/11/08.

${ }^{2}$ Doutorando em Ciência e Tecnologia de Alimentos/UFV. E-mail: marcosartori@ufv.br

${ }^{3}$ Mestranda em Ciência e Tecnologia de Alimentos/UFV. E-mail: fatimamslima@yahoo.com.br

${ }^{4}$ Professor do Departamento de Tecnologia de Alimentos da Universidade Federal de Viçosa. E-mail: rperez@ufv.br

${ }^{5}$ Professor do Departamento de Informática da Universidade Federal de Viçosa. E-mail: mnacif@ufv.br

${ }^{6}$ Professor do Departamento de Engenharia de Produção/UFV E-mail: danielledias@ufv.br
} 


\section{Introdução}

A necessidade de energias mais limpas, também influenciada pela futura escassez do petróleo, impulsionou a introdução dos biocombustíveis na matriz energética brasileira. Assim, dentro das novas tendências de utilização dos biocombustíveis no Brasil, há preocupação com a potencialização da produção e com a utilização de oleaginosas diversas.

No país, são diversas as alternativas de oleaginosas para produção de óleos vegetais, pois se trata de um país tropical, com dimensões continentais, onde o desafio colocado é o do aproveitamento das potencialidades regionais. Isso é válido tanto para culturas já tradicionais, como soja, amendoim, girassol, mamona e dendê, quanto para novas alternativas, como pinhão manso, nabo forrageiro, pequi, buriti, macaúba e outra grande variedade de oleaginosas. Dessa forma, além dos ganhos econômicos previstos, promovem-se a fixação do homem no campo e a diminuição do êxodo rural, cujos benefícios são evidentes.

Além da produção de mamona, há perspectiva de implantação de unidades de extração de óleo por associações de agricultores familiares, com vistas em favorecer a agregação de valor ao produto. Ainda que não seja a atividade principal, a extração de óleo vegetal possibilitará ao agricultor obter uma renda mínima junto a essa atividade, complementando a renda das famílias envolvidas no processo. Concomitantemente, devido à necessidade constante de mão-de-obra nas unidades, é possível garantir um número mínimo de empregos ao longo do ano, sendo que, para ocupar essas vagas, poderão ser priorizados os indivíduos envolvidos com a comunidade onde acontece a produção em regime de agricultura familiar.

Mediante a importância social desse tipo de empreendimento, assim como a necessidade de propostas que apresentem maior viabilidade para pequenos produtores de mamona, Sartori (2007) desenvolveu uma análise econômica de três diferentes conjuntos de unidades de extração de óleo de mamona vinculada à Agricultura Familiar, na região do semi-árido mineiro. No estudo, o autor analisou três opções de estruturas de 
Marco Antônio Sartori, Fátima Machado de Souza Lima, Ronaldo Perez, Mauro Nacif Rocha \& Danielle Dias Sant'Anna Martins

implantação de unidades de esmagamento. As duas primeiras privilegiaram a descentralização das unidades de extração mecânica, com a utilização de pequenas prensas dispersas na região produtora de mamona, enquanto a terceira opção envolveu uma unidade de extração por solvente centralizada. Os três modelos analisados pelo autor apresentaram viabilidade econômico-financeira, o que permite efetivas implantações.

Embora essa avaliação tenha sido proposta para o semi-árido mineiro, os modelos podem ser adaptados a realidades de outras regiões. Nesse sentido, verifica-se que a região centro-norte do estado da Bahia tem grande tradição na produção de mamona, sendo esta cultura intensiva na utilização de mão-de-obra e desempenha importante função social, especialmente em regiões com altas taxas de desemprego.

Assim, com o intuito de propor alternativas de agregação de valor à mamona produzida nessa região, sugere-se a organização dos produtores para implantar unidades de extração de óleo. Nesse sentido, admitindose a viabilidade técnica e econômica da atividade, torna-se necessária a identificação dos locais onde poderão ser instaladas as unidades processadoras de mamona, de forma mais viável, ou seja, onde os custos de transporte e instalação sejam minimizados.

A discussão é criada em decorrência das diversas alternativas de lugares para localização. Assim, a análise requer informações detalhadas sobre oferta de matéria-prima e produtos no local de processamento. Modelos sofisticados de análises e técnicas devem ser empregados para orientar, efetivamente, a identificação das melhores alternativas (DONDA JÚNIOR, 2002).

De acordo com Ballou (2006), a identificação de locais para instalações fixas ao longo da rede logística é um problema de decisão importante, que dá formato e estrutura ao sistema logístico inteiro. As decisões sobre localização envolvem a determinação do número, a localização das instalações, e os seus respectivos tamanhos. 
Dessa forma, o objetivo deste trabalho é realizar um estudo que identifique os melhores locais para instalação de unidades produtoras de óleo vegetal, considerando as variáveis que influenciam o custo de transporte da mamona e o respectivo transporte do óleo vegetal produzido. Duas dessas variáveis, talvez as mais importantes, são a localização dos fornecedores de matérias-primas, nesse caso, os municípios produtores de mamona na região do centro-norte do estado da Bahia, e a localização do principal consumidor direto do produto, a unidade de biodiesel localizada no município de Candeias, também no estado da Bahia.

\section{Referencial teórico}

\subsection{Teoria locacional}

De acordo com Lopes e Caixeta Filho (2000), a determinação do local de produção de determinado produto sempre foi uma preocupação até mesmo para os economistas clássicos, mesmo que de forma superficial. Um dos primeiros cientistas a estudar o problema de localização foi o alemão Von Thünen, no ano de 1826. Esse autor procurou determinar a influência das cidades na produção agrícola, bem como a distribuição espacial das culturas em função de seu valor, constituindo-se no que se convencionou chamar de "anéis de Von Thünen".

Com o surgimento da programação linear, em meados da década de 40, em especial do modelo de transporte, puderam ser introduzidas situações mais complexas que a original. Pôde-se, então, trabalhar com várias regiões de demanda e com várias regiões de oferta de matéria-prima. Segundo Bressler e King (1970), citados por Lopes e Caixeta Filho (2000), uma das vantagens de trabalhar com modelos multirregionais consiste em poder determinar, simultaneamente, o fluxo de produtos e os preços relativos de mercado.

Conforme Weber (1971), citado por Lam e Seldin (2004), a teoria de localização de plantas industriais começa por definir fatores locacionais 
Marco Antônio Sartori, Fátima Machado de Souza Lima, Ronaldo Perez, Mauro Nacif Rocha \& Danielle Dias Sant'Anna Martins

importantes na definição do local a ser ocupado. Para esse autor, esses fatores podem ser divididos em específicos (economias de custos alcançadas por um número pequeno de empresas) e gerais (economias de custos alcançadas por qualquer indústria). Os fatores gerais ainda podem ser separados em regionais (capazes de influenciar a escolha da localização entre regiões) e aglomerativos ou desaglomerativos (fatores que provocam a concentração ou a dispersão em uma região).

Um grande avanço na determinação da localização foi alcançado a partir da utilização de novas formas de modelagem, como a programação inteira, mais especificamente a inteira mista, que considera variáveis binárias no modelo, a programação dinâmica e a programação estocástica, que tornaram possível um maior relaxamento das pressuposições envolvidas no modelo tradicional de transporte (LOPES e CAIXETA FILHO, 2000).

\subsection{O desenvolvimento do modelo de localização}

No processo de localização de unidades agroindustriais de extração de óleo de mamona no estado da Bahia, é necessária a identificação de todos os fatores que interferem no processo de formulação do problema de localização. Segundo Williams (1993), o termo modelo é, normalmente, utilizado para caracterizar estruturas que representam objetos ou cenários.

Conforme Caixeta Filho (2004), um modelo matemático é uma estrutura que procura representar a realidade simplificadamente; na maioria das vezes, os modelos matemáticos são elaborados com o objetivo de escolher uma solução ótima. Hiller e Lieberman (1988) definiram uma solução ótima como uma solução viável que possui o valor mais favorável à funçãoobjetivo, dependendo se o objetivo é maximizar ou minimizar a função. A obtenção da solução ótima é dependente das variáveis de decisão, as quais podem estar sujeitas a uma série de restrições ou limitações.

Segundo Hiller e Lieberman (1988), a programação linear é uma ferramenta para o planejamento de atividades que visem à obtenção de um resultado ótimo, respeitando as alternativas viáveis. Para tal, na 
formulação do problema a ser resolvido por programação linear seguemse alguns passos básicos. Inicialmente, deve ser definido o objetivo básico do problema, ou seja, a otimização a ser alcançada. Para que essa função objetivo seja matematicamente especificada, devem ser definidas as variáveis de decisão envolvidas. Essas variáveis, normalmente, estão sujeitas a uma série de restrições, normalmente representadas por inequações. Todas essas expressões, entretanto, devem estar de acordo com a hipótese principal da programação linear, ou seja, todas as relações entre as variáveis devem ser lineares, o que implica proporcionalidade das quantidades envolvidas (CHVÁTAL, 1983).

Lopes (1997) destacou os avanços na modelagem de localização a partir da utilização da programação inteira-mista, especificamente a utilização de variáveis binárias no modelo. Assim, tornou-se possível testar, para cada região, as diversas capacidades de processamento, procurando-se, dessa forma, não só a localização que minimiza os custos de transporte, como também a melhor capacidade de processamento para a região. De acordo com esse autor, a teoria da localização, em termos de programação, pode ser entendida como uma variação do modelo de transporte, que, em conjunto com a programação inteira, constitui um ferramental bastante poderoso para determinação do melhor local para instalação de uma indústria.

Com relação às aplicações de modelos de localização ótima com o auxílio de programação inteira-mista, alguns trabalhos podem ser destacados. Dentre eles, o de Ramos e Caixeta Filho (2002), que desenvolveram um modelo matemático de localização de packing-houses para regiões representativas do estado de São Paulo, de acordo com sete diferentes capacidades de processamento dessas plantas e com vistas à minimização dos custos de implantação, processamento e transporte da laranja. Os principais parâmetros considerados no modelo incluem os custos de transporte e de processamento da laranja e os custos de implantação de packing-houses de diferentes capacidades, bem como a oferta e demanda de cada região considerada no estudo. 
Marco Antônio Sartori, Fátima Machado de Souza Lima, Ronaldo Perez,

Mauro Nacif Rocha \& Danielle Dias Sant'Anna Martins

Oliveira e Santos (2004) determinaram a localização ótima de novas agroindústrias de esmagamento de soja no estado do Mato Grosso. As variáveis consideradas foram os custos de transporte de grãos (soja) até a agroindústria, a produção de grãos (quantidade) e o custo de instalação e ampliação de novas agroindústrias.

Canziani (1991) estudou a localização de fábricas de suco de laranja concentrado no norte e noroeste do estado do Paraná, visando à minimização dos custos de coleta e reunião da produção, de processamento e de distribuição do produto final. $\mathrm{O}$ autor considerou, no modelo, economia de escala no transporte e processamento, projetando várias situações de oferta de matéria-prima.

\section{Metodologia}

Para identificação dos possíveis locais de implantação de unidades produtoras de óleo de mamona, foi inicialmente realizado um mapeamento dos principais fornecedores de matérias-primas, nesse caso, os municípios produtores de mamona da mesorregião centro-norte do estado da Bahia e, ainda, da unidade de biodiesel da PETROBRAS, localizada na cidade de Candeias - BA, potencial consumidora do óleo vegetal produzido, conforme Figura 1. 


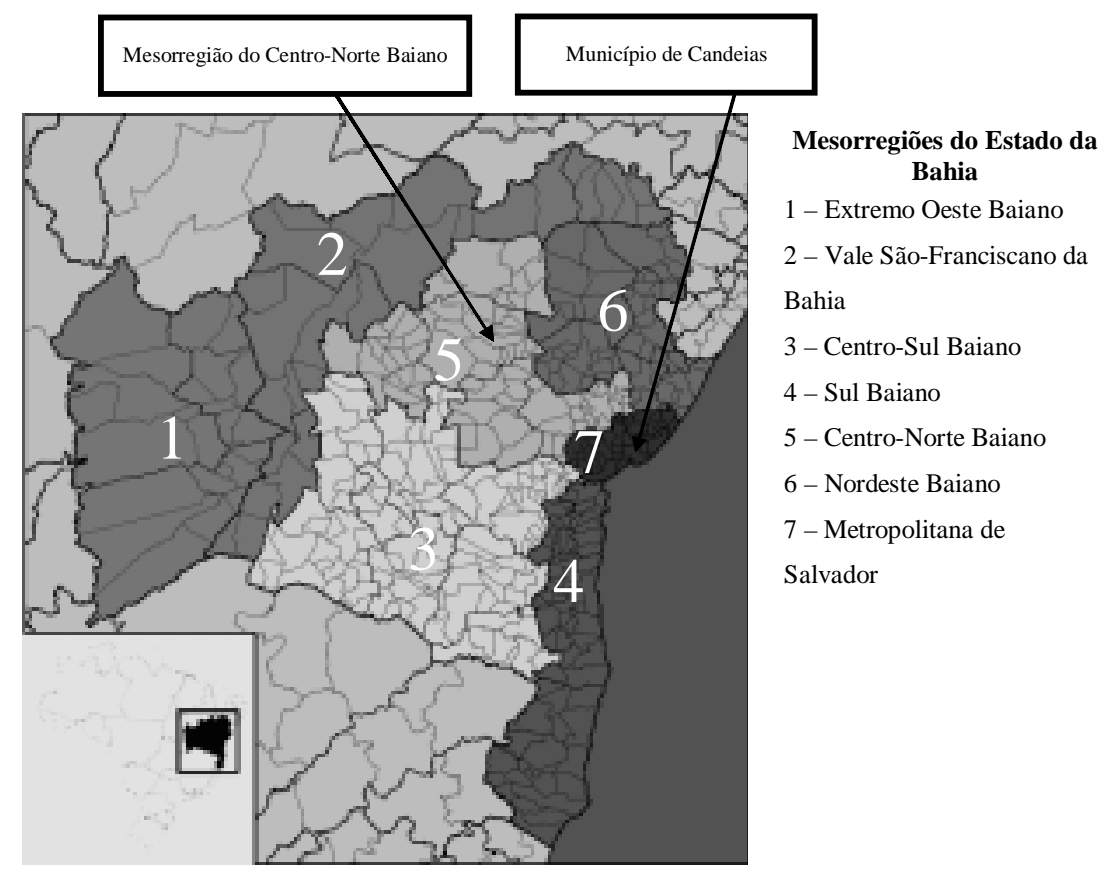

Fonte: Adaptado de Wikimedia (2008).

Figura 1 - Mapa do Estado da Bahia com suas respectivas mesorregiões.

De acordo com os dados fornecidos pelo IBGE (2006), foram 55 cidades produtoras de mamona na região centro-norte do estado da Bahia, conforme Tabela 1, onde são identificadas também as capacidades individuais de produção de mamona de cada município. 
Marco Antônio Sartori, Fátima Machado de Souza Lima, Ronaldo Perez, Mauro Nacif Rocha \& Danielle Dias Sant'Anna Martins

Tabela 1 - Relação das 55 cidades produtoras de mamona na região do centro-norte baiano com as respectivas quantidades produzidas, em 2006

\begin{tabular}{|c|c|}
\hline Cidades & $\begin{array}{c}\text { Produção } \\
\text { (ton/ano) }\end{array}$ \\
\hline América Dourada & 300 \\
\hline Andorinha & 33 \\
\hline Antônio Gonçalves & 152 \\
\hline Baixa Grande & 18 \\
\hline Barra do Mendes & 36 \\
\hline Barro Alto & 1296 \\
\hline Boa Vista do Tupim & 225 \\
\hline Caém & 380 \\
\hline Cafarnaum & 3312 \\
\hline Caldeirão Grande & 504 \\
\hline Campo Formoso & 900 \\
\hline Canarana & 2000 \\
\hline Capim Grosso & 7 \\
\hline Central & 2700 \\
\hline Filadélfia & 432 \\
\hline Gentio do Ouro & 147 \\
\hline Iaçu & 405 \\
\hline Ibipeba & 162 \\
\hline Ibiquera & 32 \\
\hline
\end{tabular}

\begin{tabular}{|c|c|}
\hline Cidades & $\begin{array}{c}\text { Produção } \\
\text { (ton/ano) }\end{array}$ \\
\hline Ibititá & 2700 \\
\hline Iraquara & 1575 \\
\hline Irecê & 240 \\
\hline Itaberaba & 27 \\
\hline Itatim & 62 \\
\hline Itiúba & 368 \\
\hline Jacobina & 609 \\
\hline Jaguarari & 196 \\
\hline João Dourado & 400 \\
\hline Jussara & 1800 \\
\hline Lajedinho & 86 \\
\hline Lapão & 2100 \\
\hline Macajuba & 36 \\
\hline Miguel Calmon & 455 \\
\hline Mirangaba & 720 \\
\hline Morro do Chapéu & 4800 \\
\hline $\begin{array}{c}\text { Mulungu do } \\
\text { Morro }\end{array}$ & 2650 \\
\hline Ourolândia & 3150 \\
\hline Pindobaçu & 228 \\
\hline
\end{tabular}

\begin{tabular}{|c|c|}
\hline Cidades & $\begin{array}{c}\text { Produção } \\
\text { (ton/ano) }\end{array}$ \\
\hline Piritiba & 450 \\
\hline Ponto Novo & 184 \\
\hline Presidente Dutra & 4320 \\
\hline Quixabeira & 22 \\
\hline Ruy Barbosa & 72 \\
\hline São Gabriel & 4320 \\
\hline $\begin{array}{c}\text { São José do } \\
\text { Jacuípe }\end{array}$ & 53 \\
\hline Saúde & 308 \\
\hline Senhor do Bonfim & 340 \\
\hline Serrolândia & 180 \\
\hline Souto Soares & 1680 \\
\hline Tapiramutá & 45 \\
\hline Uibaí & 2700 \\
\hline Umburanas & 1080 \\
\hline Várzea da Roça & 56 \\
\hline Várzea do Poço & 102 \\
\hline Várzea Nova & 2610 \\
\hline
\end{tabular}

Fonte: IBGE, 2006.

Para definição das cidades candidatas a receberem prensas para a extração de óleo, admitiram-se 18 cidades candidatas, sendo a escolha dessa quantidade baseada na produção de mamona igual ou superior a 900 toneladas/ano, ou seja, com condições de suprimento de matériaprima igual ou superior a 3 toneladas/dia, considerando-se 300 dias de processamento no ano. Ainda, determinou-se que a cidade de Candeias, também no estado da Bahia, seria considerada o ponto de recepção para o óleo de mamona produzido, em razão da demanda dessa matéria-prima para produção de biodiesel. 
A Figura 2 ilustra a distribuição das cidades produtoras de mamona na mesorregião centro-norte baiano, com destaque para as cidades candidatas à instalações de usinas de processamento de mamona.

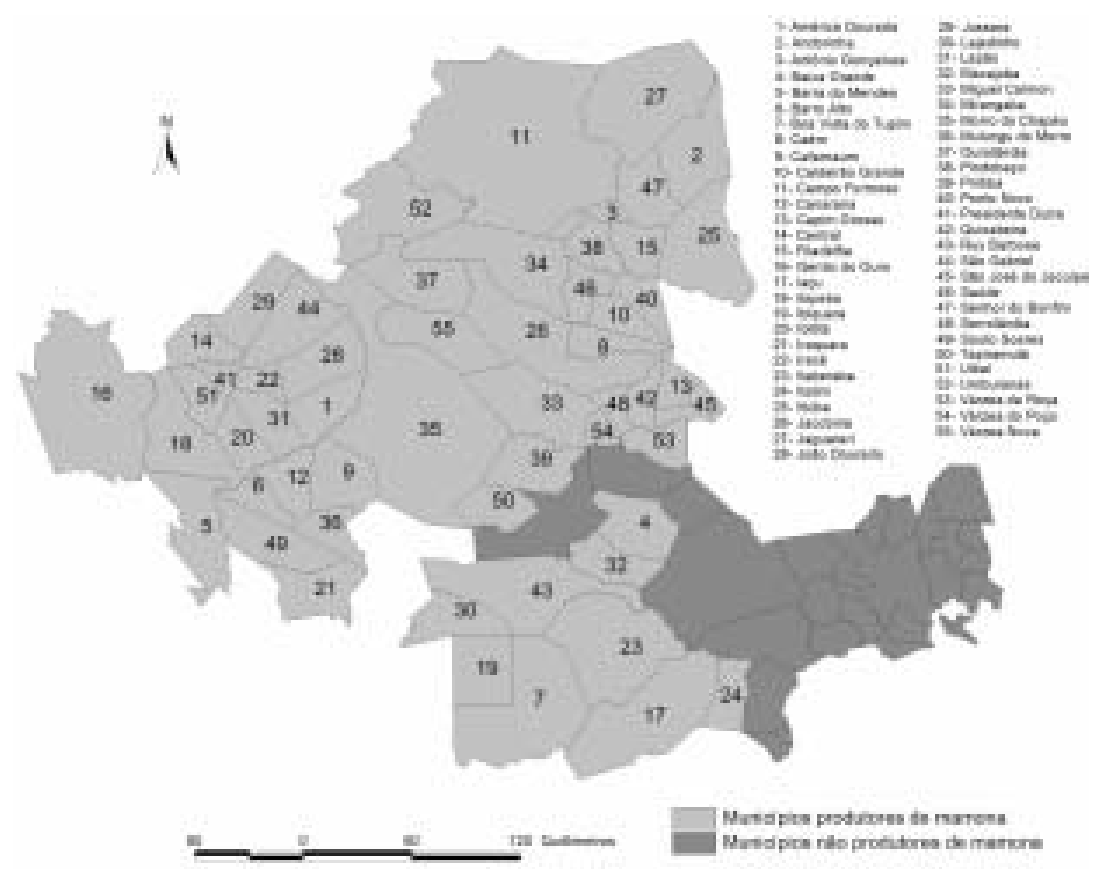

Fonte: Adaptado de IBGE, 2008.

Figura 2 - Mapa da Mesorregião Centro-Norte Baiano, com destaque para os municípios produtores de mamona e as cidades candidatas à instalação de usinas de processamento.

Com vistas em buscar o número ótimo de unidades produtoras e as melhores localizações para essas instalações, foram identificadas as distâncias entre os 55 municípios produtores de mamona e os 18 municípios com maior produção de mamona, e entre estes e o município de Candeias, receptor final de óleo. No cálculo da distância real entre as cidades produtoras de mamona e as cidades candidatas a receberem as 
Marco Antônio Sartori, Fátima Machado de Souza Lima, Ronaldo Perez, Mauro Nacif Rocha \& Danielle Dias Sant'Anna Martins

usinas de extração de óleo, e entre estas últimas e a cidade de Candeias - BA, foi utilizado o software GUIA QUATRO RODAS - PRO.

O Guia Quatro Rodas Rodoviário - PRO é um software desenvolvido, especialmente, para planejamento e otimização de rotas rodoviárias com múltiplas cidades que têm funcionalidades voltadas para quem trabalha direta ou indiretamente com transporte rodoviário no Brasil. Por meio do Guia Quatro Rodas Rodoviário PRO, determinou-se para cada par de cidades a menor distância entre elas.

Admitiu-se ainda um raio de captação de mamona de $50 \mathrm{~km}$ em cada município, já que a produção da oleaginosa se encontra dispersa ao redor de cada núcleo urbanizado. $\mathrm{O}$ custo de transporte de mamona considerado foi de $\mathrm{R} \$ 0,10 /\left(\right.$ ton $\left.^{*} \mathrm{~km}\right)$, enquanto o de transporte do óleo foi de $\mathrm{R} \$ 0,15$ / (ton*km), conforme dados adaptados do SIFRECA (2008).

A partir dos cenários propostos por Sartori (2007), foram então consideradas as opções de instalação de unidades de processamento de mamona com capacidades de 7,5 e 22,5 toneladas de matéria-prima diariamente. Os custos de instalação individuais considerados foram de $\mathrm{R} \$ 913.757,00$ e R \$ 2.103.501,00, respectivamente.

Com vistas em atingir os objetivos definidos no presente trabalho, foi desenvolvido um modelo para determinar a localização ótima de usinas de extração de óleo de mamona captada na região centro-norte do estado da Bahia, considerando a usina de biodiesel localizada na cidade de Candeias como a receptora final do óleo vegetal produzido. Na modelagem do problema foi adotado o método de localização exata, que constituiu no desenvolvimento de um modelo de programação inteira mista, o qual compreende os problemas de programação matemática em que a função objetivo e as restrições são lineares, sendo algumas variáveis do tipo inteiro e outras do tipo real. O software utilizado foi o XPRESS MP*.

www.dashoptimization.com 
O modelo desenvolvido está representado a seguir:

$$
\begin{aligned}
& \text { FO : Min } 0,10 * \sum_{i=1}^{55} \sum_{j=1}^{18} C_{i j} X_{i j}+0,15 * \sum_{j=1}^{18} D_{j} W_{j}+\sum_{j=1}^{55} B Y_{j} \\
& \text { s.a. } \\
& \sum_{j=1}^{55} X_{i j}=S_{i}, \forall i=1,2 \ldots 55 \\
& \sum_{i=1}^{18} X_{i j}=2,5 *\left(W_{j}\right), \forall j=1,2 \ldots 18 \\
& \sum_{i=1}^{55} X_{i j} \leq B_{j} Y_{j}, \forall j=1,2 \ldots 55 \\
& Y \in\{0,1\}
\end{aligned}
$$

em que $F O$ é a função objetivo que visa à minimização dos custos de transporte entre as cidades fornecedoras de mamona e as unidades de produção de óleo vegetal, e destas com a unidade de biodiesel; $i$, índice que define a cidade de origem (produtor de mamona); $j$, índice que define $\mathrm{a}(\mathrm{s})$ cidade(s) de destino (produção de óleo vegetal); $k$, índice que define a cidade de destino (usina de biodiesel); $C i j$, matriz de distâncias entre as cidades produtoras e as cidades candidatas à instalação das unidades de extração de óleo; $D j$, distância entre as cidades candidatas à instalação das unidades de extração de óleo e a unidade de biodiesel em Candeias - BA; Si, vetor que determinará a capacidade de produção de mamona de cada cidade; $X i j$, matriz de quantidade de mamona transportada da cidade $i$ para a cidade $j ; Y j$, variável binária que indica se há, ou não, a instalação na cidade candidata; $W j$, quantidade de óleo vegetal a ser transportada das cidades $j$ à cidade de Candeias - BA; $B j$, capacidade de processamento de cada unidade produtora de óleo de mamona, igual a 7,5 ou 22,5 ton/dia de mamona; $F$, custo de instalação de uma usina de extração de óleo de mamona com capacidade de processamento de 7,5 ou 22,5 ton/dia, cujos valores são $\mathrm{R} \$ 913.757,00$ e $\mathrm{R} \$ 2.103 .501,00$, respectivamente. 
Marco Antônio Sartori, Fátima Machado de Souza Lima, Ronaldo Perez,

Mauro Nacif Rocha \& Danielle Dias Sant'Anna Martins

A primeira restrição representa a limitação de produção de cada cidade. Por essa restrição, a quantidade de mamona que sai da cidade $i$ deve ser igual à quantidade de mamona produzida nessa cidade. Pela restrição dois, percebe-se que a massa do óleo que deixa a unidade de extração $j$ é igual a $40 \%$ da massa de mamona produzida pelas cidades $i$. Nessa restrição, considerou-se que a mamona tem um rendimento de $40 \%$ de óleo.

A terceira restrição representa a disponibilidade de capacidade de recepção de mamona pelas unidades candidatas à instalação da usina de extração de óleo, e ainda restringe esse cálculo apenas às unidades onde realmente haverá instalação. Essa restrição se dá pela utilização da variável binária Y.

A quarta restrição apresenta a variável binária $Y$, ou seja, restringe os valores de $\mathrm{Y}$ a zero ou 1 . O valor 1 ocorrerá para determinada localidade quando a solução do modelo apontá-la como localização ótima.

\section{Resultados e discussões}

Ao aplicar o modelo proposto no software XPRESS MP, obtiveram-se, como resultado ótimo, as localizações de unidades de produção de óleo vegetal a partir de mamona em oito municípios: Cafarnaum, Campo Formoso, Canarana, Morro do Chapéu, Mulungu do Morro, Ourolândia, Presidente Dutra e São Gabriel. 


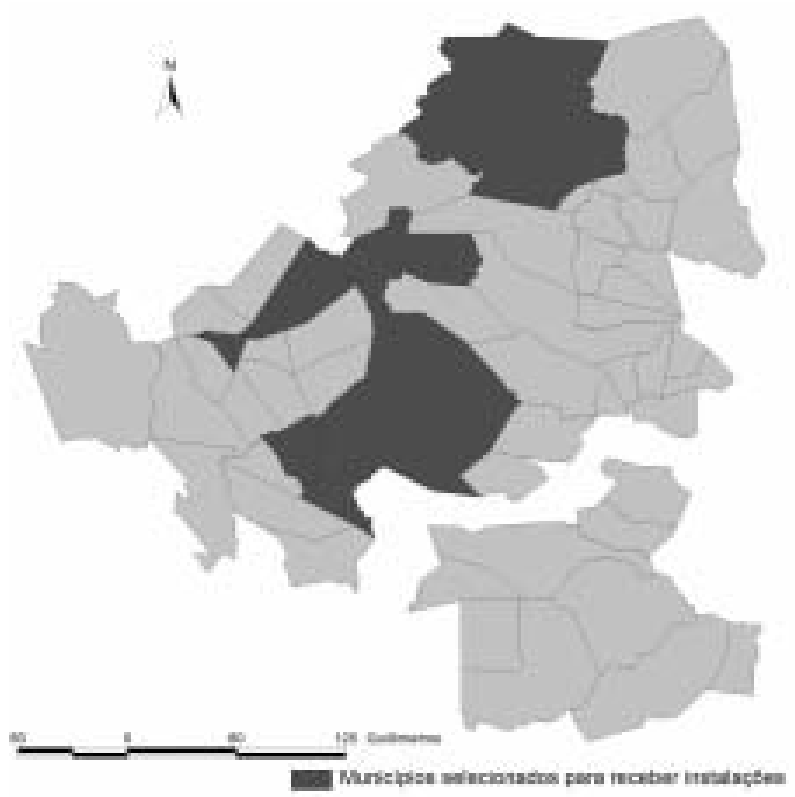

Fonte: Adaptado de IBGE, 2008.

Figura 3 - Mapa da mesorregião centro-norte baiano, com destaque para os municípios produtores de mamona e as cidades candidatas à instalação de usinas de processamento.

Essas oito usinas de extração de óleo, todas com capacidade de processamento de 22,5 ton/dia, deverão processar toda a mamona produzida na região e enviar a produção para a unidade de biodiesel, localizada no município de Candeias. As unidades, juntas, produziram 21.505 toneladas de óleo de mamona anualmente, o que equivale a $40 \%$ da quantidade de mamona processada (53.765 toneladas).

As unidades de processamento de mamona instaladas recebem mamona dos municípios relacionados abaixo, o que é ilustrado nas Figuras 4 a 7. 
Marco Antônio Sartori, Fátima Machado de Souza Lima, Ronaldo Perez, Mauro Nacif Rocha \& Danielle Dias Sant'Anna Martins

- Unidade de Cafarnaum: Cafarnaum, Irecê, Jussara, Lapão (54\% da produção) e Central (10\%).

- Unidade de Campo Formoso: Andorinha, Antônio Gonçalves, Baixa Grande, Caém, Caldeirão Grande, Campo Formoso (37,7\%), Capim Grosso, Filadélfia, Itatim, Itiúba, Jacobina, Jaguarari, Macajuba, Miguel Calmon, Mirangaba, Pindobaçu, Piritiba (37\%), Ponto Novo, Quixabeira, São José do Jacuípe, Saúde, Senhor do Bonfim, Serrolândia, Várzea da Roça e Várzea do Poço.

a

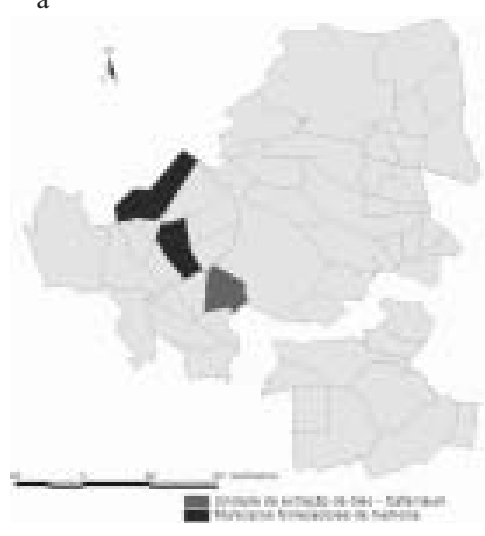

$\mathrm{b}$

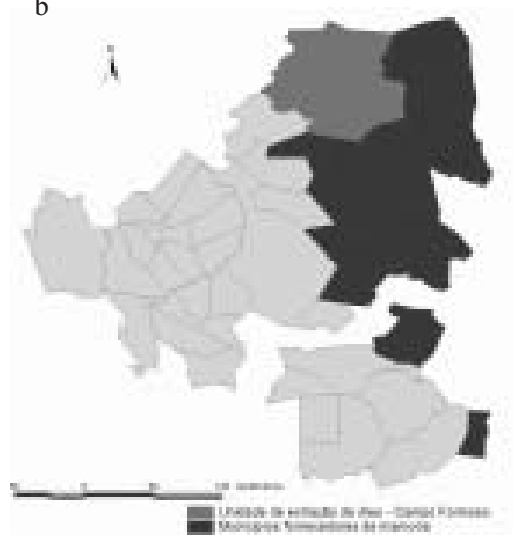

Fonte: Adaptado de IBGE, 2008.

Figura 4 - Mapa ilustrativo da unidade de processamento de mamona localizada em (a) Cafarnaum e (b) Campo Formoso, com os respectivos fornecedores.

- Unidade de Canarana: Barra do Mendes, Barro Alto (36\%), Canarana, Gentil do Ouro, Ibipeba, Ibititá, Lapão (46\%) e Uibaí $(10,0 \%)$.

- Unidade de Morro do Chapéu: América Dourada, Boa Vista do Tupim, Iaçu, Ibiquera, Itaberaba, João Dourado, Lajedinho (86\%), Morro do Chapéu, Piritiba (63\%), Ruy Barbosa, Tapiramutá e Várzea Nova $(3,5 \%)$. 
(a)

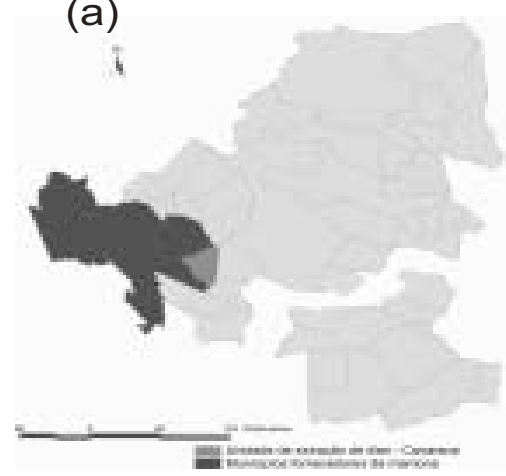

(b)

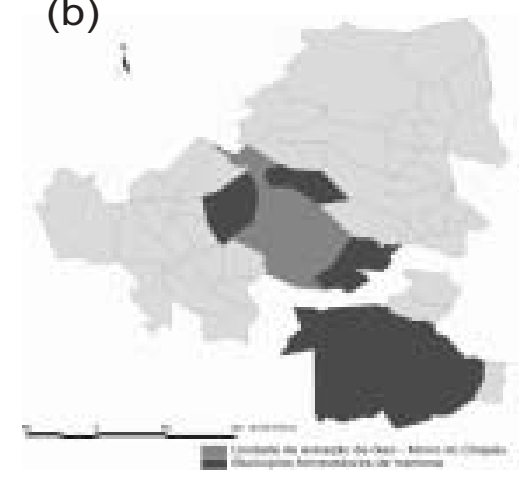

Fonte: Adaptado de IBGE, 2008.

Figura 5 - Mapa ilustrativo da unidade de processamento de mamona localizada em (a) Canarana e (b) Morro do Chapéu, com os respectivos fornecedores.

- Unidade de Mulungu do Morro: Barro Alto (64\%), Iraquara, Lajedinho (14\%), Mulungu do Morro e Souto Soares.

- Unidade de Ourolândia: Ourolândia, Umburanas e Várzea Nova $(96,5 \%)$.
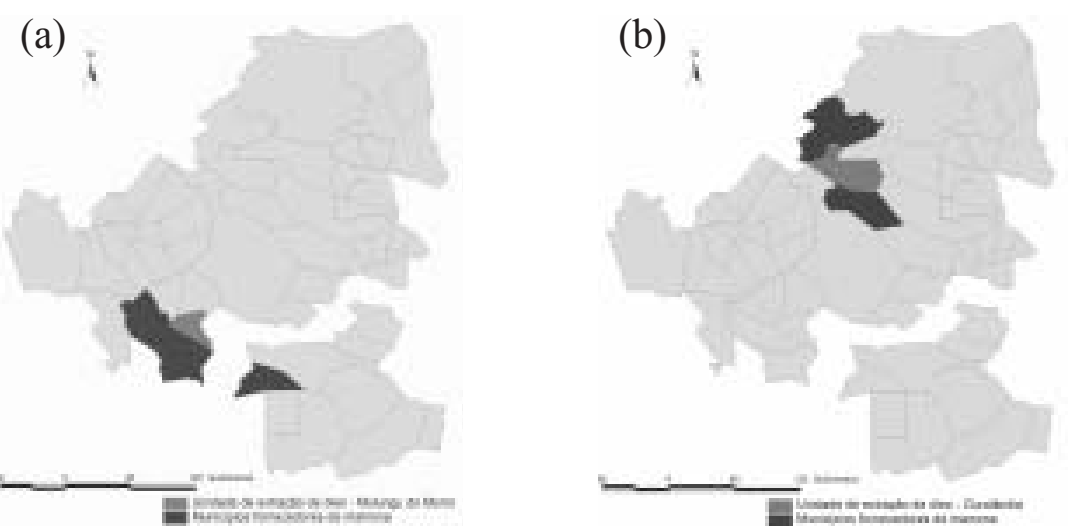

Fonte: Adaptado de IBGE, 2008.Figura 6 - Mapa ilustrativo da unidade de processamento de mamona localizada em (a) Mulungu do Morro e (b) Ourolândia, com os respectivos fornecedores. 
Marco Antônio Sartori, Fátima Machado de Souza Lima, Ronaldo Perez,

Mauro Nacif Rocha \& Danielle Dias Sant'Anna Martins

- Unidade de Presidente Dutra: Presidente Dutra e Uibaí (90\%).

- Unidade de São Gabriel: São Gabriel e Central (90\%).
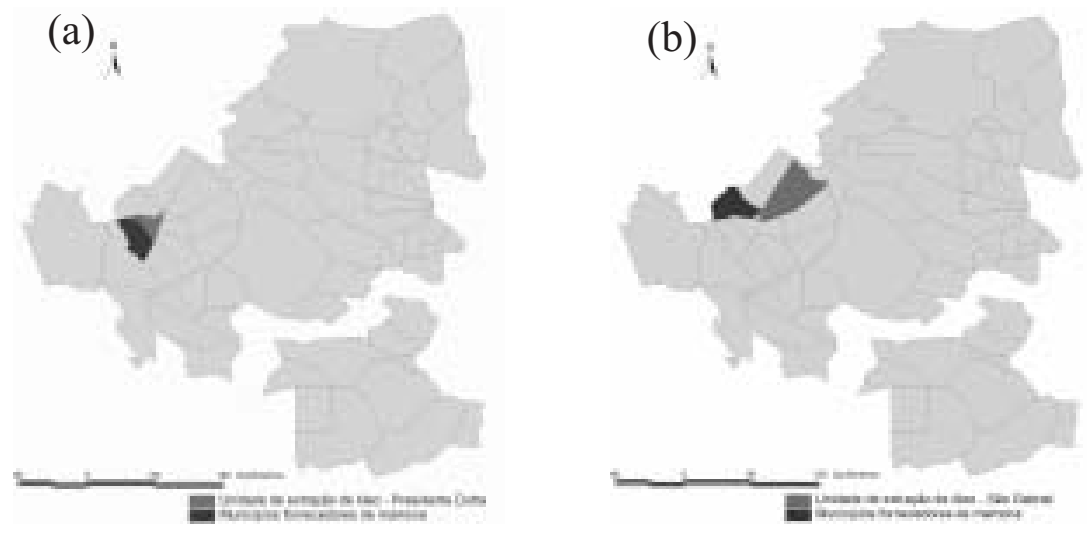

Fonte: Adaptado de IBGE, 2008.Figura 7 - Mapa ilustrativo da unidade de processamento de mamona localizada em (a) Presidente Dutra e (b) São Gabriel, com os respectivos fornecedores.

No que tange à distribuição espacial das plantas processadoras, observouse que o modelo priorizou a instalação de unidades em áreas mais próximas aos municípios maiores produtores. Verificou-se que foram privilegiadas as prensas com capacidade de processamento de 22,5 toneladas de mamona por dia. Em se tratando das prensas maiores, elas oferecem redução nos investimentos, quando comparadas às proporções entre investimento e escala de processamento. O custo de instalação foi de $\mathrm{R} \$ 18.227 .700,00$, enquanto o custo anual de transporte de mamona foi de $\mathrm{R} \$ 252.292,00$ e o de transporte de óleo, de $\mathrm{R} \$ 1.274 .650,00$.

Percebe-se nítida diferença entre os custos de transporte, justificada pelo maior custo unitário do transporte de óleo em relação à mamona $\mathrm{e}$ devido à maior distância entre os municípios onde se localizam as prensas e o município de Candeias. 
A distância média entre as unidades de produção de óleo vegetal e a cidade de Candeias é de 394,9 km, e o custo de transporte de óleo entre as unidades de processamento e a unidade de biodiesel é de $\mathrm{R} \$ 59,27$ por tonelada. O custo de transporte de mamona é de $\mathrm{R} \$ 4,69$ por tonelada transportada, e a distância média entre os produtores de mamona e as unidades de processamento, de 46,92 Km. Verifica-se, ainda, grande diferença entre o custo de instalação das prensas e o de transporte da mamona e óleo produzido.

Nessas condições, com base nos dados obtidos por Sartori (2007), serão gerados 236 empregos em decorrência da atividade de processamento da mamona, independentes dos existentes no campo. Além disso, relacionam-se à atividade diversas outras fontes de renda, como a própria atividade de transporte, assim como o oportuno desenvolvimento da cultura em outras áreas, promovendo o crescimento regional.

\section{Conclusão}

Este estudo identificou os melhores municípios para instalações de usinas de extração de óleo de mamona na região centro-norte do estado da Bahia, privilegiando duas alternativas de prensas que poderão ser utilizadas na extração de óleo de mamona pela agricultura familiar. Os resultados obtidos apontam a implantação de oito unidades produtoras nessa região, dadas as condições propostas, e contribuem para auxiliar a tomada de decisão sobre uma cadeia de produção de biodiesel em pleno desenvolvimento no Brasil.

Os resultados apresentados indicam as melhores localidades para instalação de unidades de esmagamento de mamona, o que proporciona ao estado da Bahia, aos seus empresários e aos agricultores orientação para instalação dessas unidades. Essa orientação é baseada em análises de minimização de custos de transporte, item de elevado impacto na competitividade de pequenas unidades. Essa minimização de custos de captação de oleaginosas compensa, em parte, a redução nos custos, 
Marco Antônio Sartori, Fátima Machado de Souza Lima, Ronaldo Perez, Mauro Nacif Rocha \& Danielle Dias Sant'Anna Martins

proporcionada pelo aumento de escala no esmagamento nas grandes unidades. É importante salientar que nas pequenas unidades, além de mais próximas do suprimento de matéria-prima, a ação é facilitada pela comercialização e pelo acesso ao mercado para a torta da mamona. Essa torta de mamona produzida pode retornar ao campo e ser utilizada na forma de adubo, sendo de grande utilidade para os pequenos agricultores na própria região da instalação industrial.

A agroindustrialização da mamona, vinculada à agricultura familiar a partir de pequenas agroindústrias, pode proporcionar ainda aumento da produção agrícola na região Nordeste, o que favorece a geração de emprego e a renda no meio rural. Já o estado e os municípios ganham por aumentar a abrangência de suas políticas de inserção de famílias em ações de desenvolvimento. Esse tipo de análise, aliada ao estudo viabilidade, já apóia ações vinculadas à Cooperativa de Agricultores do Município de Morro do Chapéu - BA, pois proporciona minimização do risco, favorece o aumento da competitividade e viabiliza negócios.

\section{Referências}

CAIXETA FILhO, J.V. Pesquisa operacional: Técnicas de otimização aplicadas a Sistemas Agroindustriais. São Paulo: Atlas, 2004. 169 p.

BALLOU, R. H. Gerenciamento da cadeia de suprimentos: planejamento, organização e logística empresarial. Porto Alegre: Bookman, 2006. 616p.

CANZIANI, J.R.F. Simulação sobre a implantação da indústria de suco concentrado de laranja no Estado do Paraná. Piracicaba - SP, ESALQ/USP. 111p. Dissertação (Mestrado em Economia Aplicada) Escola Superior de Agricultura "Luiz de Queiroz", Universidade de São Paulo, 1981. 
CHVÁTAL, V. Linear Programming. New York: W. H. Freeman and Company, 1983.

DONDA JÚNIOR, A. Fatores influentes no processo de escolha da localização agroindustrial no Paraná: estudo de caso de uma agroindústria de aves. Florianópolis, SC: UFSC, 2002. 141 p. Dissertação (Mestrado em Engenharia de Produção) - Universidade Federal de Santa Catarina, 2002.

FAPESB - Fundação de Amparo à Pesquisa do Estado da Bahia. Áreas Prioritárias: Biodiesel. 2005. Disponível em: http:// www.fapesp.ba.gov.br. Acesso em: 28/09/2005.

HILLER, F.; LIEBERMAN, G.J. Introdução à pesquisa operacional. 3.ed. São Paulo: Edusp, 1988. 803 p.

IBGE. Sistema IBGE de Recuperação Automática - SIDRA. Banco de Dados Agregados. Produção Agrícola Municipal - Quantidade Produzida. 2006. Disponível em: <www.ibge.gov.br>. Acesso em 23/03/ 2008.

IBGE - Instituto Brasileiro de Geografia e Estatística. Malha Municipal do Estado da Bahia em 2005. Rio de Janeiro: IBGE, 2008. Disponível em: <ftp://geoftp.ibge.gov.br/mapas/malhas_digitais/municipio_2005/ E500/Proj_Geografica/ArcView_shp/Uf/BA/>. Acesso em: 25 jul. 2008.

LAM, B.; SELDIN, R. Modelos de Localização - Teoria e Relevância para as Indústrias. 2004. Encontro de Engenharia de Produção da UFRJ, Rio de Janeiro, 2004. CD Rom.

LOPES, R. L. Suinocultura no estado de Goiás: aplicação de um modelo de localização. Piracicaba - SP. ESALQ/USP, 1997, 95 p. Dissertação (Mestrado em Economia Aplicada) - Escola Superior de Agricultura “Luiz de Queiroz”, Universidade de São Paulo, 1997. 
Marco Antônio Sartori, Fátima Machado de Souza Lima, Ronaldo Perez,

Mauro Nacif Rocha \& Danielle Dias Sant'Anna Martins

LOPES, R. L.; CAIXETA FILHO, J. V. Suinocultura no Estado de Goiás: Aplicação de um Modelo de Localização. 2000. Pesquisa Operacional Vol. 20, No. 2, p. 213-232, 2000.

MA, F.; HANNA, M. A. Biodiesel production: a review. Bioresource Technology, Volume 70, Issue 1, Pages 1-15, October 1999.

OLIVEIRA, N.M., SANTOS, H.N., Agroindústria no estado de Mato Grosso: uma aplicação de um modelo de localização. In: $1^{\circ}$ Congresso Luso-Brasileiro de Tecnologias de Informação e Comunicação na Agropecuária. Santarém - Portugal, 2004.

RAMOS, S. Y., CAIXETA FILHO, J. V. Distribuição espacial de packing-houses de laranja no Estado de São Paulo: uma aplicação da teoria da localização. Revista de Economia e Sociologia Rural, Vol. $40 \mathrm{~N}^{\circ} 3,2002$.

SARTORI, M.A. Análise de cenários de extração de óleo vegetal para produção de biodiesel na região do norte de Minas Gerais. Viçosa, MG: UFV, 2007. 75 p. Dissertação (Mestrado em Ciência e Tecnologia de Alimentos) - Universidade Federal de Viçosa, 2007.

SIFRECA - Sistema de Informação de Fretes. Fretes Rodoviários. 2008. Disponível em: http://sifreca.esalq.usp.br. Acesso em: 27/05/2008.

WIKIMEDIA FOUNDATION. Disponível em: http:// c o m m o n s. wi k i m e d i a.o $\mathrm{rg} / \mathrm{w} \mathrm{i} \mathrm{k}$ i / Category:Locator_maps_of_mesoregions_of_Bahia> Acesso em 10 de junho de 2008.

WILLIAMS, H.P. Model building in mathematical programming. 3.ed. Chichester: Wiley \& Sons, 1993. 353 p. 
Abstract: The objective of this work is to identify the best location to install oil mills to process vegetable oil, obtained from castor, in the North Central Region in the State of Bahia, Brazil. Fifty five cities in that region have been identified as producers of this vegetable as so as their respective productivity and distance between them and the cities for the installation of the oil mills. Besides, the city of Candeias was elected to receive the produced oil, since there is a factory (PETROBRAS) that biodiesel castor oil. Aiming to encourage local small scale farming and processing of castor, produced at that region, two models of screw presses have been chosen, with capacities of 7.5 and 22.5 tons of castor's oil per day to extract the oil. A mathematical model has been developed and, using the software XPRESS MP Release 2007, satisfactory results have been reached, that indicated eight cities for the installation of the mills.

Keywords: localization, castor oil, transportation cost. 